\title{
Revista
}

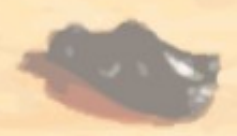

\section{OFICINA DE FLAUTA DOCE: RELATO DA EXPERIÊNCIA DO PROCESSO DE MUSICALIZAÇÃO DE CRIANÇAS}

DOI:10.5965/19843178912014170

http://dx.doi.org/10.5965/19843178912014170

Luana Moína Gums ${ }^{1}$

Maira Ana Kandler ${ }^{2}$

\begin{abstract}
RESUMO
Esse texto tem como objetivo relatar sobre a experiência pedagógico-musical vivenciada no ano de 2013 em uma Oficina de Flauta Doce para crianças de 8 a 12 anos. A Oficina de

Flauta Doce foi campo de estágio da disciplina Estágio Curricular Supervisionado do curso de Licenciatura em Música. A fundamentação teórica foi baseada na flauta doce como instrumento musicalizador e performático (CUERVO, 2009) e no ensino coletivo de instrumentos (TOURINHO, 2003; 2007; BARBOSA, 1997). Foram realizadas atividades de apreciação, percepção musical, composição e execução das flautas doce soprano e contralto. Além disso, foram feitas apresentações musicais e a participação na gravação de um CD com as Oficinas de Música do MusE 2013.

Palavras chave: Educação musical. Flauta doce. Ensino coletivo de instrumento. Estágio curricular. Relato de experiência.
\end{abstract}




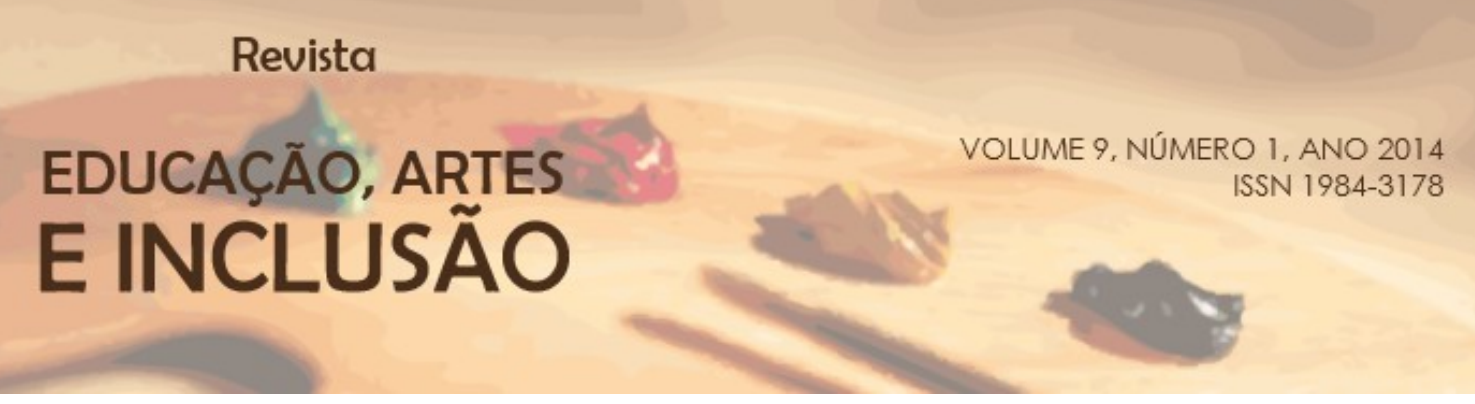

ABSTRACT

This text aims to report the pedagogical and musical experience occured in 2013 on a Recorder Workshop for children 8-12 years old. The Recorder Workshop was the place of teaching practice or the Music Undergraduate Program. The theoretical background was based on the recorder as an instrument for musical learning and for performance (CUERVO, 2009), and collective instrumental teaching (TOURINHO, 2003; 2007;

BARBOSA, 1997). Appreciation, musical perception, composition and recorder performance activities were carried. In addition, musical performances were presented and a CD with the Workshop results was recorded.

Keywords: Music Education. Recorder. Collective Instrumental Teaching. Teaching practice. Experience Report. 


\section{Revista

\section{Introdução}

Este texto tem por objetivo relatar a experiência pedagógico-musical que foi vivenciada na disciplina Estágio Curricular Supervisionado do curso de Licenciatura em Música da Universidade do Estado de Santa Catarina - UDESC. Essa experiência foi realizada junto ao Programa de Extensão do Grupo de Pesquisa Música e Educação MusE, que oferece Oficinas de Música dentro do espaço da Universidade para crianças de 6 a 12 anos. No ano de 2013 foram oferecidas quatro turmas: três Oficinas de Musicalização e uma Oficina de Flauta Doce. Neste relato será apresentada a prática realizada junto à turma da Oficina de Flauta Doce, na qual participaram oito alunas ${ }^{3}$, com faixa etária de 8 a 12 anos.

Um dos objetivos do Programa de Extensão do Grupo de Pesquisa MusE, é criar espaços para formação de educadores musicais, inserindo os acadêmicos do curso de Licenciatura em Música nas práticas pedagógicas. Semanalmente é realizada uma reunião onde estão presentes uma das coordenadoras do Programa de Extensão, as professoras orientadoras e todos os acadêmicos que atuam nas oficinas. Nessas reuniões são discutidos os planejamentos das aulas, as escolhas metodológicas, repertório e materiais didáticos utilizados nas oficinas, visando oferecer um momento para reflexão em grupo e também para a troca de experiências músico-pedagógicas entre os acadêmicos e professores orientadores.

A Oficina de Flauta Doce teve aulas semanais com duração de uma hora e esse horário foi estendido para atividades de gravação ou apresentações. As aulas foram

3 Somente meninas se inscreveram para participar das aulas. 


\section{Revista

ministradas em uma sala do Departamento de Música da UDESC, a qual estava equipada com instrumentos de percussão, piano, computador com acesso à internet e projetor, quadro pautado, estantes para partitura e flautas doce soprano, contralto, tenor e baixo, oferecendo a infraestrutura necessária para o desenvolvimento das atividades. A condução das aulas ficou a cargo de um bolsista de extensão e de uma aluna da disciplina de Estágio Curricular Supervisionado, sendo supervisionados por uma professora orientadora.

O objetivo da Oficina foi promover o aprendizado da flauta doce através de atividades em que as crianças executassem o instrumento, compusessem suas próprias músicas, analisassem a sua produção musical e a de outros instrumentistas. Outro objetivo foi explorar a flauta doce de forma lúdica e criativa, desenvolvendo domínio progressivo das habilidades de interpretação, criação e registro sonoro, ampliando o conhecimento das crianças sobre o universo sonoro do instrumento. Além disso, foram realizadas atividades de apreciação do repertório do instrumento, com músicas de diferentes gêneros, culturas e períodos históricos e exercícios para o desenvolvimento de habilidades de leitura musical com partituras convencionais e não convencionais.

Cada aluna participante da Oficina foi instruída a trazer uma flauta doce soprano de digitação barroca. A escolha entre a flauta doce com digitação barroca ou germânica foi feita com base na revisão de literatura realizada sobre o assunto. Em uma pesquisa realizada para levantamento do material existente para o ensino de flauta doce, Garcia (2003) expõe que todos os métodos consultados por ela recomendam

a utilização do dedilhado barroco. [...] O dedilhado germânico ainda é frequentemente utilizado em vários países que, mesmo na Alemanha, não é utilizado para fins sérios e, cujo principal defeito é a impossibilidade de uma perfeita afinação em todos os graus cromáticos (GARCIA, 2003, p. 3). 


\section{Revista

De acordo com a autora, a flauta doce com digitação barroca possibilita a execução de toda escala cromática com boa afinação e relativa facilidade nas tonalidades com sustenidos. Além disso, é possível tocar todas as tonalidades com resultados musicais aceitáveis.

A seguir será apresentada a fundamentação teórica que embasou a prática pedagógico-musical, será descrita a abordagem metodológica desenvolvida durante as aulas e por fim, serão apresentadas as considerações sobre a experiência docente.

\section{Fundamentação teórica}

A flauta doce é um instrumento antigo que sobreviveu durante décadas sem transformações na sua estrutura. No Brasil, passou a ser utilizada como instrumento musicalizador a partir do século XX pelos seguintes motivos: 1) fácil iniciação técnica de execução e memorização; 2) é acessível financeiramente; 3) pode ser utilizada com outros instrumentos musicais em sala de aula na construção de arranjos; 4) possibilita acesso a diferentes culturas, períodos e gêneros e, 5) reúne um grande repertório de valor artístico (CUERVO, 2009, p. 23). Dessa forma, de acordo com Cuervo (2009), a flauta doce proporciona um processo de aquisição de habilidades inicialmente mais acessíveis, podendo ser um instrumento utilizado em práticas de conjunto e explorado na apreciação musical de alunos em qualquer nível de aprendizado musical. Como discorrem Cuervo e Pedrini (2010, p. 53), "utilizar a flauta doce como uma das possibilidades no ensino de música é abrir caminho de exploração e criação, quebrar pré-conceitos, valorizar as preferências musicais dos alunos, sem deixar de ampliá-las”.

As atividades realizadas na Oficina de Flauta Doce tiveram como objetivo principal a execução do instrumento. Assim como no trabalho de Weiland (2008/2009), o processo de ensino realizado na Oficina, teve como base a proposta de ensino musical de 


\section{Revista

Swanwick (2003) e buscou o "desenvolvimento musical do aluno, incluindo diversas formas de interação com a música, integrando as atividades de composição, execução e apreciação, apoiadas na técnica e literatura musicais” (WEILAND, 2008/2009, p. 51), não se limitando ao domínio de habilidades específicas e estudo técnico da execução da flauta doce. Dessa maneira, as alunas da oficina aprenderam a tocar o instrumento, tendo acesso às várias formas do fazer musical: compor, criar, ouvir, ler e escrever em partituras convencionais e não convencionais, tocando em conjunto e individualmente e também com acompanhamento de outros instrumentos.

As aulas e atividades na Oficina de Flauta Doce foram desenvolvidas em grupo, seguindo os princípios do ensino coletivo. O ensino coletivo de instrumentos é uma prática antiga no ensino musical, que se manteve afastada até a segunda metade do século XX, quando ganhou mais espaço nas escolas de música (TOURINHO, 2003, p. 1). Esse tipo de ensino possibilita que os envolvidos tenham outras referências musicais além do professor, pois de acordo com Tourinho (2007),

pode-se argumentar em favor do ensino coletivo que o aprendizado se dá pela observação e interação com outras pessoas, a exemplo de como se aprende a falar, a andar, a comer. Desenvolvem-se hábitos e comportamentos que são influenciados pelo entorno social, modelos, ídolos (TOURINHO, 2007, p. 2).

Dessa forma, as alunas da Oficina de Flauta Doce aprenderam em conjunto e observando vídeos ou apresentações. Assim, os desafios foram superados com a troca de experiências na prática em conjunto.

De acordo com Barbosa (1996, p. 40), com o ensino coletivo “o aluno desenvolve a leitura musical, o domínio instrumental, a capacidade auditiva, as habilidades mentais e o entendimento musical.” Além desses fatores, o ensino coletivo gera entusiasmo por 


\section{Revista

fazer o aluno se sentir parte do grupo, causa também uma competição saudável e desenvolve uma capacidade de tocar em conjunto desde o início das aulas (BARBOSA, 1996). Além das características apresentadas que tornam a flauta doce um instrumento adequado para ser utilizado no ensino coletivo, ela possibilita o trabalho com diferentes timbres, usando outras flautas do quarteto: contraltos, tenores e baixos.

\section{Abordagem metodológica}

A Oficina de Flauta Doce teve início no mês de março de 2013 e finalização no mês de dezembro do mesmo ano. As primeiras aulas foram dedicadas à apresentação da flauta doce e suas partes (pé, corpo e bisel) e à exploração dos sons que podem ser realizados por cada uma dessas partes. Outros aspectos abordados foram o aprendizado da postura corporal apropriada para a execução da flauta doce, o conhecimento dos pontos de apoio do instrumento - polegar direito, polegar esquerdo e boca - e a articulação necessária para tocar o instrumento. Neste mesmo período foram introduzidas as primeiras notas musicais e suas respectivas digitações, partindo de atividades de eco desenvolvidas com a percepção sonora. Inicialmente foram adotadas músicas com três notas: si, lá e sol.

Para o aprendizado e a prática de novas notas foi escolhido um repertório com arranjos a duas e três vozes, além da utilização da flauta doce soprano e da flauta doce contralto. Essa última foi utilizada na execução de ostinatos, realizados pelas crianças e pelos professores, juntamente com a melodia na flauta doce soprano. A Figura 1 apresenta o arranjo da música “Asa Branca” com ostinato na flauta doce contralto. 


\section{Revista
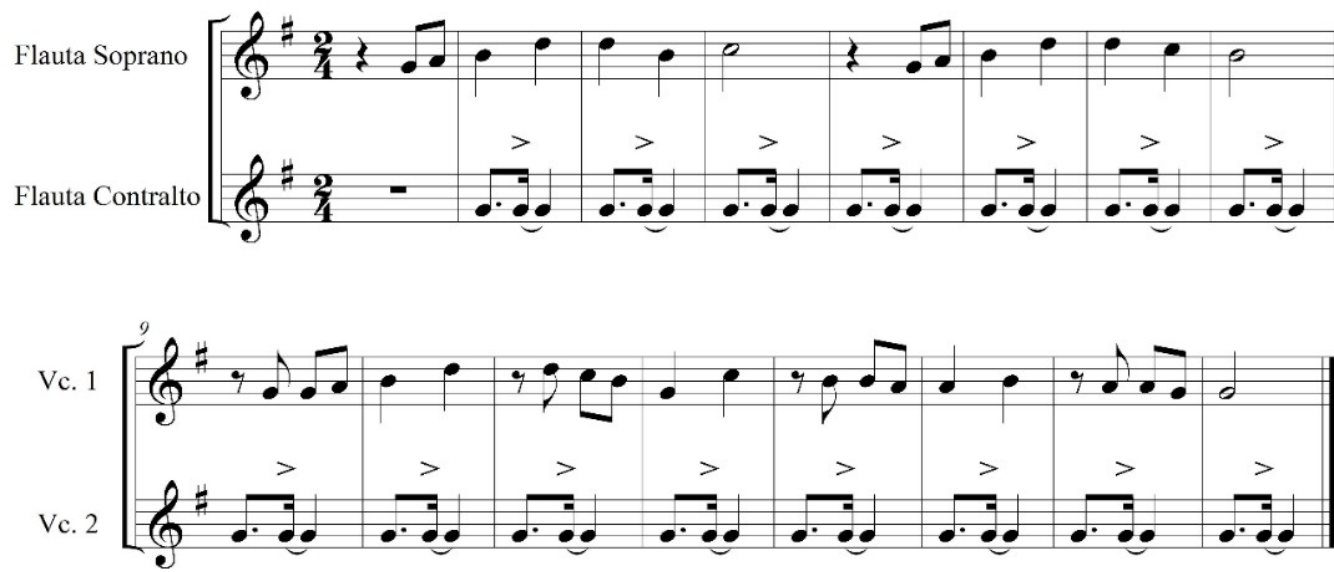

Figura 1: Transcrição da música "Asa Branca” com ostinato.

Fonte: Elaboração das próprias autoras.

Posteriormente foram adicionadas outras notas ao ostinato, conforme o desenvolvimento e interesse das alunas.

Os arranjos das músicas executadas durante a Oficina de Flauta doce tiveram acompanhamento do piano, xilofone ou percussão. A utilização de instrumento harmônico no acompanhamento das músicas teve como objetivo auxiliar o desenvolvimento da afinação na flauta doce. Em alguns arranjos, além de tocar a flauta doce, as alunas tocaram também instrumentos de percussão como triângulo, pandeiro e xilofones, contando com o acompanhamento do bolsista no piano ou violão. Para auxiliar a condução do trabalho e para que as alunas pudessem estudar em casa as músicas aprendidas durante as aulas, foi elaborada, a partir de uma pesquisa sobre repertório de flauta doce, uma apostila com músicas folclóricas brasileiras e de outros países. Ao longo 


\section{Revista

da apostila foram incluídos pentagramas e folhas em branco, para que as atividades de composição e de percepção pudessem ser grafadas.

A escrita musical foi ensinada através de partitura convencional e não convencional, sendo a mesma um dos conteúdos trabalhados no decorrer das aulas. Utilizando a partitura convencional alguns conhecimentos de leitura musical foram trabalhados, tais como o pentagrama, claves, notas e pausas. Esse recurso foi uma ferramenta utilizada para facilitar a execução do repertório proposto. A utilização de partituras não convencionais fez parte do processo como uma forma alternativa do registro e processo de leitura musical. Para Cuervo e Pedrini (2009, p. 57) as formas não convencionais de grafia devem ser trabalhadas em paralelo com o processo musical, pois

a escrita não convencional, seja ela gráfica, por roteiro ou analogia, deve permear o processo de desenvolvimento musical. Não vemos esses recursos ampliados como um meio de chegar à escrita convencional pentagramática (pauta tradicional), tampouco como um estágio evolutivo anterior ou posterior (CUERVO; PEDRINI, 2010, p. 57).

Atividades de apreciação musical também foram realizadas com repertórios de diversos estilos e períodos. Essas atividades forneceram às alunas um material sonoro contextualizado, auxiliando no processo de composição e construção de arranjos.

As gravações e apresentações - públicas ou dentro da própria turma - fizeram parte das atividades realizadas, seguidas de reflexões dos alunos e professores sobre tais experiências. Discutir com os alunos sobre o processo de gravar ou apresentar uma música trouxe diversas contribuições no sentido de reforçar a importância de aspectos trabalhados pelos professores durante o semestre, como a posição corporal, articulação, estudo do instrumento em casa e comprometimento com as atividades. Essas discussões também aproximaram o contato entre as alunas, pois elas só se encontravam durante a aula.

Aos poucos, as alunas se tornaram colegas além do fazer musical, fazendo com que se ajudassem nas atividades de composição, contribuindo com opiniões sinceras sobre 


\section{Revista

as apresentações individuais. Um exemplo dessas contribuições encontra-se na fala de uma das alunas sobre a execução de uma colega: “Acho que a primeira parte da música que você tocou ficou muito bonita, mas a segunda parte você precisa estudar mais, se você quiser posso tocar junto” (Notas de campo, 18/06/2013). Foi observado que essas colocações faziam com que as alunas se sentissem responsáveis pelo seu próprio aprendizado e pelo crescimento musical da turma, não deixando a tarefa de estimular o grupo apenas para os professores. A interação entre as alunas e a liberdade em comentar sobre a produção musical das colegas são reflexos da prática musical proporcionada pela metodologia do ensino coletivo.

No decorrer das aulas, foram realizadas atividades de composição partindo de poemas, temas ou motivos criados previamente, tendo em vista o desenvolvimento criativo das crianças. Uma atividade de composição foi realizada partindo de haicais ${ }^{4}$ trazidos pelos professores. A atividade constituiu na realização de duas composições com as notas já aprendidas em aula - sol, lá, si, dó, ré - tendo a possibilidade de utilizar a letra do haicai na música ou de ser somente instrumental. Um dos grupos utilizou a letra do seu haicai e o outro grupo optou por uma versão instrumental. No decorrer do semestre, a composição instrumental, chamada pelas compositoras de “Outono”, passou a ser trabalhada pela turma toda. As alunas que compuseram a música explicaram o processo utilizado para os professores e para turma: primeiro elas decidiram quais notas gostariam de usar e depois a temática do haicai. Elas escolheram a temática “Outono” para o haicai de Humberto del Maestro: "Começo de chuva... A tempestade faz festa, no meio da rua." Assim, elas foram combinando as notas em uma melodia que lembrasse a temática. A música utilizou todas as notas que a turma já havia aprendido e também uma nota nova (mi grave), o que foi considerado um desafio para a turma. A forma da música foi dividida 


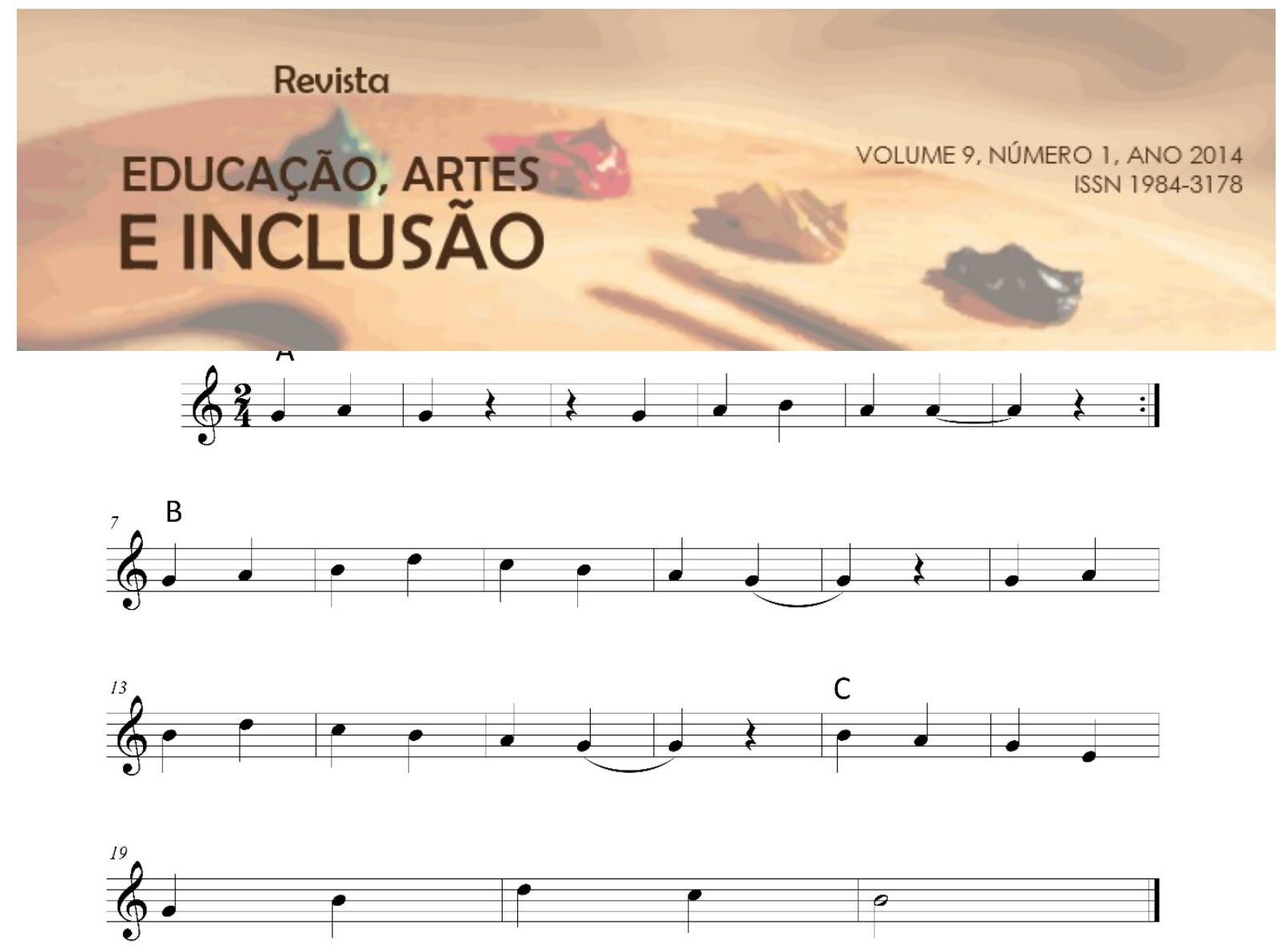

em três partes com repetição e pausas. A seguir, a Figura 2 apresenta a transcrição da composição das alunas da Oficina de Flauta Doce.

Figura 2: Transcrição da composição "Outono".

Fonte: Elaboração das próprias autoras.

A composição foi executada no final do primeiro semestre de 2013, em uma apresentação para os pais dos alunos que participam das Oficinas do Grupo de Pesquisa MusE, com um arranjo com acompanhamento do piano. No segundo semestre, os professores fizeram um arranjo da composição para quarteto de flautas doce, piano e guitarra com a forma musical "tema e variações". A música foi gravada em estúdio com a participação das alunas para fazer parte do CD das Oficinas de Música do MusE 2013. As atividades de composição foram de grande importância, pois as alunas se observaram como autoras do seu próprio trabalho e como flautistas. Além disso, puderam expandir seus conhecimentos musicais e reforçar conceitos aprendidos durante as aulas. 


\section{Revista

Desafios foram enfrentados durante o processo de ensino realizado na Oficina de Flauta Doce. Apesar de terem apresentado interesse nas atividades, foi observada uma oscilação na motivação das alunas. Essa questão se refletiu tanto na assiduidade do grupo quanto na prática diária do instrumento. Isso pode ser explicado pelo fato das atividades ocorrerem apenas uma vez na semana. Além disso, o formato do projeto de estágio elaborado para a realização da Oficina de Flauta Doce, que atribuiu maior importância ao processo e não teve o objetivo de chegar a um determinado nível no resultado final, gerou desafios no sentido de inserir o instrumento como um elemento integrante do cotidiano das alunas. As apresentações no final dos dois semestres se mostraram importantes para auxiliar essa problemática. O período que antecedia as apresentações coincidia com os momentos de maior produção das alunas, evidenciando uma preocupação em construir um resultado satisfatório para o grupo.

\section{Considerações finais}

A flauta doce é um instrumento de fácil acesso e quando integrada com diversos tipos de atividades pedagógico-musicais amplia o repertório musical dos alunos respeitando o repertório já conhecido com acesso a diferentes períodos e gêneros musicais (CUERVO, 2009). O ensino coletivo, por sua vez, tem características próprias: faz com que os participantes aprendam em conjunto sem a referência somente de um professor (TOURINHO, 2007; BARBOSA, 1996). Essas características foram observadas durante o processo de ensino com as alunas da Oficina de Flauta Doce.

As aulas regulares, o processo de construção e reflexão do planejamento, realizados individual e coletivamente pela estagiária, bolsista de extensão e orientadora fez com que o trabalho tivesse uma continuidade e um crescimento de forma geral. Tais 


\section{Revista

aulas produziram aspectos importantes a serem observados, como por exemplo, o comprometimento dos envolvidos com a prática pedagógico-musical. É importante ressaltar o papel do professor durante essas aulas, estimulando e ampliando as ideias musicais das alunas, além de uma variedade de outras atitudes cruciais: mostrar interesse e valorizar as músicas que as alunas compõem, tocar com frequência durante as aulas peças diferentes das que são familiares para o grupo, conversar sobre como está sendo o processo de estudo em casa, dar espaço para as alunas falarem sobre seu desenvolvimento pessoal e mostrar as músicas feitas em casa ou na escola. O papel do orientador também foi observado como de grande ajuda para a estagiária e para o bolsista, tanto com a participação efetiva em algumas das aulas quanto nas orientações semanais, discutindo problemáticas observadas, possíveis sugestões, questões positivas e outras a revisar, visando o desenvolvimento das aulas.

Com o decorrer do projeto, foi possível perceber que as alunas se desenvolveram musicalmente, participando das atividades e apresentando suas críticas sobre o processo de aprendizado individual e do grupo. Foi observado que depois da apresentação no fim do primeiro semestre de 2013 as alunas se sentiram mais responsáveis com o fazer musical, possivelmente porque mostraram o que aprenderam e quiseram continuar a aprender mais.

O encerramento da Oficina de Flauta Doce se deu com uma apresentação das músicas feitas durante o semestre, para os pais e convidados. Essa apresentação foi feita em conjunto com as outras três Oficinas de Musicalização. Junto com a apresentação foi feito o lançamento do CD das Oficinas de Música do MusE 2013, que reuniu as composições realizadas durante o ano pelos alunos de todas as Oficinas. 


\section{Revista

\section{REFERÊNCIAS}

BARBOSA, Joel L. S. Considerando a viabilidade de inserir música instrumental no ensino de Primeiro Grau. Revista da ABEM, Porto Alegre, n. 3, p. 39-49, 1996.

CUERVO, Luciane. Musicalidade na performance com a flauta doce. 2009. Dissertação. (Mestrado em Educação) - Faculdade de Educação, Universidade Federal do Rio Grande do Sul, Porto Alegre.

CUERVO, Luciane; PEDRINI, Juliana. Flauteando e criando: reflexões e experiências sobre criatividade na aula de música. Música na educação básica. Porto Alegre, v. 2, n. 2, 2010.

GARCIA, Eda do Carmo Pereira. Flauta doce soprano: construindo uma habilidade técnica em educação musical. I Colóquio do NEM. Políticas públicas e ações sociais em educação musical, Florianópolis, SC. Anais...XII Encontro Anual da ABEM, Florianópolis, SC, Outubro 21 a 24, 2003, p. 279-284 (CD ROM)

SWANWICK, Keith. Ensinando música musicalmente. São Paulo: Moderna, 2003.

TOURINHO, Cristina. Ensino Coletivo de Instrumentos Musicais: crenças, mitos, princípios e um pouco de história. Anais... XVI Encontro Nacional da ABEM e Congresso Regional da ISME, América Latina, 2007.

A formação de professor para o ensino coletivo de instrumento. XII Encontro Anual da Associação Brasileira de Educação Musical e Colóquio do NEM, Florianópolis, SC. Anais... XII Encontro Anual da ABEM, Florianópolis, SC, Outubro 21 a 24, 2003, p. 51-57.

WEILAND, Considerações sobre o ensino de flauta doce a partir de uma abordagem cognitiva musical. Anais... VI Fórum de pesquisa científica em arte. Curitiba, 2008-2009. 